\title{
Frequência de suplementação e fontes de proteína para recria de bovinos em pastejo no período seco: desempenho produtivo e econômico ${ }^{1}$
}

\author{
Nelcino Francisco de Paula², Joanis Tilemahos Zervoudakis², Luciano da Silva Cabral², \\ Daniel Marino Guedes de Carvalho ${ }^{2}$, Luciana Keiko Hatamoto-Zervoudakis ${ }^{2}$, Eduardo \\ Henrique Bevitori Kling de Moraes ${ }^{2}$, André Alves de Oliveira ${ }^{2}$
}

\author{
${ }^{1}$ Pesquisa parcialmente financiada pelo CNPq e pela FAPEMAT. \\ 2 Programa de Pós-Graduação em Ciência Animal, Universidade Federal de Mato Grosso (UFMT) - Av. Fernando Correa da Costa sn. \\ Cuiabá-MT, CEP: 78060-900.
}

RESUMO - Dois experimentos foram conduzidos com o objetivo de avaliar os efeitos da frequência de suplementação com duas fontes proteicas sobre o desempenho produtivo e econômico e o consumo e a digestibilidade dos nutrientes em bovinos em pastejo sob suplementação durante o período seco do ano. Foram utilizados 20 animais anelorados, não-castrados com 10 meses de idade e peso médio inicial de 208,43 kg, distribuídos em quatro piquetes de capim-marandu (Brachiaria brizantha, cv. Marandu), cada um com 1,6 ha. Ambos os experimentos foram estruturados em arranjo fatorial $2 \times 2$, com dois suplementos (com farelo de soja e com farelo de algodão de alta energia) e duas frequências de suplementação (diariamente ou três vezes por semana). Não houve interação fontes proteicas $\times$ frequências de suplementação para nenhuma das características de desempenho produtivo e econômico. As fontes proteicas não influenciaram o ganho médio diário, mas a frequência de fornecimento afetou o desempenho, que foi melhor nos animais sob suplementação três vezes $/ \mathrm{semana}(0,670 \mathrm{~kg} / \mathrm{dia})$. O maior retorno econômico foi obtido com a oferta do suplemento com farelo de algodão três vezes por semana. A frequência de suplementação afetou o consumo de nutrientes, enquanto a fonte proteica do suplemento teve efeito somente sobre o consumo de extrato etéreo, que foi maior nos animais que consumiram o suplemento com farelo de algodão. O suplemento com farelo de algodão alta energia proporcionou maior digestibilidade da proteína bruta da dieta. O fornecimento de suplemento três vezes por semana, além de reduzir os custos da suplementação, possibilita desempenho superior ao obtido com a suplementação diária. A utilização do farelo de algodão de alta energia em suplementos múltiplos em substituição ao farelo de soja é satisfatória, principalmente do ponto de vista econômico.

Palavras-chave: frequência de suplementação, ganho de peso, pastagem, suplemento

\section{Supplementation frequency and proteins sources for growing of steers in pasture during the dry season: productive and economical performance}

ABSTRACT - Two experiments were carried out with the objective of evaluating the effects of the frequency of supplementation with two proteins sources on productive and economical performance (experiment 1) and the nutrients digestibility of steers in supplemented pasture during the dry season over a year. It was used twenty weaned zebu calves at the age of 10 months and initial live weight (LW) of $208.43 \mathrm{~kg}$, distributed in four paddocks of Brachiaria brizantha cv. Marandu, each one with 1.6 ha. Both experiments were structured in $2 \times 2$ factorial arrangement with two supplements (with soybean meal and high energy cottonseed meal). There was no protein sources $\times$ supplementation frequency interaction for any of the economical and productive performance traits. The protein sources didn't affect the daily average gain, but the frequency of supply affected performance, which was better in the animals under supplementation at three times a week $(0.670 \mathrm{~kg} / \mathrm{day})$. The highest economic return was obtained with the offer of supplement with cottonseed meal three times a week. The frequency of supplementation affect the nutrients intake, while the protein source of the supplement had effect only on the ethereal extract intake, which was higher in the animals that consumed the supplement with cottonseed meal. The supplement with high energy cottonseed meal provided higher digestibility of diet crude protein. The supply of supplement three times a week, not only reduces the costs of supplementation, but it possibilities a higher performance than the one obtained with daily supplementation. The use of higher energy cottonseed meal in multiple supplements replacing soybean meal is satisfactory mainly under economical point of view.

Key Words: gain of weight, pasture, supplement, supplementation frequency

Recebido em 9/9/2008 e aprovado em 25/3/2009.

Correspondências devem ser enviadas para: joanis@ufmt.br 


\section{Introdução}

As gramíneas forrageiras são base alimentar da bovinocultura de corte brasileira e constituem a principal fonte de nutrientes para os animais ao longo do ano. Entretanto, uma característica da produção de bovinos a pasto é a sazonalidade da produção forrageira, que promove oscilações no suprimento de nutrientes aos animais, impondo a necessidade de suplementação e/ou complementação alimentar para elevação da produtividade(Paulino et al., 2006a).

Durante o período seco do ano, a queda na quantidade e qualidade da forragem e o aumento nos constituintes fibrosos, notadamente tecidos lignificados (Van Soest, 1994), reflete negativamente na digestibilidade da matéria seca (MS) e no consumo pelos animais. Os teores de PB destas gramíneas não atingem o valor mínimo de 7\%, relatado por Minson (1990) como limitante para adequada atividade dos microrganismos do rúmen, o que compromete a utilização dos substratos energéticos fibrosos potencialmente digestíveis (Lazzarini et al., 2009).

Além disso, entre todos os custos envolvidos no processo de suplementação, o de transporte e distribuição diária dos suplementos para animais em pastejo são expressivos. Assim, o fornecimento do suplemento em menor frequência pode permitir ao pecuarista obter relação custo:benefício mais favorável, uma vez que este método permite otimização e racionalização da mão-de-obra, do combustível e de maquinários associados ao processo de suplementação.

De acordo com Farmer et al. (2004a), ruminantes consumindo forragem de baixa qualidade e sob suplementação em intervalos maiores que um dia são hábeis em manter o desempenho quando comparados com animais sob suplementação diária.

Por outro lado, tão importante quanto avaliar a eficiência produtiva da suplementação é o impacto econômico desta prática no sistema de produção. A utilização de tecnologias que possibilitem a intensificação da produção e o avanço dos índices de produtividade geralmente aumenta os custos de produção (Santos et al., 2004a). Portanto, uma vez definidos os aspectos técnicos e estratégicos da suplementação, torna-se necessária também a avaliação da viabilidade econômica.

Assim, objetivou-se avaliar os efeitos da frequência de suplementação com fontes proteicas sobre o desempenho produtivo, a viabilidade econômica, o consumo e a digestibilidade dos nutrientes de bovinos recriados em pastagem de Brachiaria brizantha cv. Marandu no período seco do ano.

\section{Material e Métodos}

Dois experimentos foram conduzidos no setor de Bovinocultura de Corte da Fazenda Experimental da Universidade Federal de Mato Grosso, localizada no município de Santo Antônio de Leverger, Mato Grosso, durante o período seco do ano, entre os meses de julho e setembro.

No experimento 1, avaliou-se o desempenho produtivo e a viabilidade econômica e, no experimento 2, estudaram-se o consumo e a digestibilidade dos nutrientes da dieta em bezerros anelorados recebendo suplementação alimentar.

Utilizaram-se 20 bezerros anelorados não-castrados com 10 meses de idade e peso vivo médio inicial de $208,43 \mathrm{~kg}$, distribuídos aleatoriamente entre as estratégias de suplementação. Ao início do primeiro experimento, todos os animais foram submetidos ao controle de endo e ectoparasitas.

A área experimental destinada aos animais foi constituída de quatro piquetes de 1,6 ha, formados com Brachiaria brizanha cv. Marandu, providos de bebedouros e cochos cobertos para fornecimento do suplemento, cujas dimensões permitiam acesso de todos os animais simultaneamente.

Avaliaram-se dois suplementos isoproteicos, constituídos de duas fontes de proteína verdadeira (farelo de soja e farelo de algodão de alta energia), fornecidos em duas freqüências semanais (Tabela 1). Os suplementos foram formulados para apresentar 32\% de PB na matéria natural e fornecidos em quantidades equivalentes a $1 \mathrm{~kg} /$ animal/dia, em diferentes frequências semanais e sempre às $10 \mathrm{~h}$.

Os animais foram pesados no início do primeiro experimento e a cada 28 dias, sem jejum, e sempre pela manhã, para monitoramento do desempenho. Após a pesagem inicial, receberam aleatoriamente um dos

Tabela 1 - Composição em ingredientes dos suplementos com farelo de algodão de alta energia e farelo de soja (\%MN)

\begin{tabular}{lcc}
\hline Ingrediente & \multicolumn{2}{c}{ Suplemento } \\
\cline { 2 - 3 } & $\begin{array}{c}\text { Farelo de algodão } \\
\text { alta energia }\end{array}$ & $\begin{array}{c}\text { Farelo } \\
\text { de soja }\end{array}$ \\
\hline Mistura mineral $^{1}$ & 6,0 & 6,0 \\
Ureia/Sulfato de amônio (9:1) & 5,0 & 2,5 \\
Milho grão moído & 24,0 & 40,5 \\
Farelo de algodão de alta energia ${ }^{2}$ & 65,0 & - \\
Farelo de soja & - & 51,0 \\
\hline 1 Suplemento mineral comercial - Ricofós 60 especial. & \\
Níveis de garantia: Ca - 198 g; P - 60 g; Na - 117 g; Mg - 5,1 g; S - 12,6 g; I - 17,7 mg; \\
Fe - 425 mg; Se - 10,4 mg; Co - 80 mg; manganês - 527 mg; F - 600 mg; Cu - \\
1.000 mg; Zn - 3.000 mg.
\end{tabular}

R. Bras. Zootec., v.39, n.4, p.873-882, 2010 
suplementos: a) com farelo de soja 3 vezes/semana (segundas, quartas e sextas-feiras); ou b) diariamente; c) com farelo de algodão alta energia (3 vezes/semana); ou d) diariamente. No segundo experimento, os animais foram pesado no primeiro e último dia.

Para reduzir a influência da variação na disponibilidade de MS de forragem entre os piquetes, a cada sete dias, procedeu-se ao rodízio dos animais entre os piquetes, mantendo-se o fornecimento dos mesmos suplementos aos animais. O primeiro experimento foi composto de três períodos experimentais de 28 dias, perfazendo um total de 84 dias para avaliação do desempenho animal e viabilidade econômica. No dia seguinte ao término do primeiro experimento, iniciou-se o segundo experimento, que teve duração de nove dias, para a avaliação do consumo e da digestibilidade.

Durante os nove dias do experimento 2, foram aplicados via oral 15 g de óxido crômico em cada animal, destinando-se seis dias para a adaptação dos animais e para que a concentração de óxido crômico nas fezes atingisse a concentração de equilíbrio e os três dias finais para coleta de amostras de fezes.

Amostras dos suplementos utilizados durante o preparo das misturas foram coletadas para posteriores análises laboratoriais. No primeiro dia de cada período experimental, foram coletadas amostras de forragem nos piquetes por meio do corte, a $5 \mathrm{~cm}$ acima do solo, de cinco áreas delimitadas por um quadrado metálico de $0,5 \times 0,5 \mathrm{~m}$, escolhidos aleatoriamente para posterior determinação da disponibilidade de matéria seca total (DMST) e matéria seca potencialmente digestível (DMSpD).

Após a coleta, as amostras de cada piquete foram pesadas e homogeneizadas. Coletaram-se, então, duas alíquotas: uma para avaliação da DMST/ha e outra para fracionamento dos componentes estruturais da planta e posterior análise das disponibilidades. Em ambos os experimentos, a amostragem da forragem consumida pelos animais foi obtida via simulação manual do pastejo, realizada no primeiro dia de cada período experimental.

Das amostras destinadas à estimação da disponibilidade total de MS de forragem, foi calculado o percentual de MS potencialmente digestível (MSpD) ofertada aos animais. Esse resultado foi obtido pelo resíduo insolúvel em detergente neutro avaliado após incubação in situ das amostras por 144 horas, segundo a equação:

$$
\mathrm{MSpD}=0,98 \mathrm{X}(100-\mathrm{FDN})+(\mathrm{FDN}-\mathrm{FDNi}),
$$

em que: $0,98=$ coeficiente de digestibilidade verdadeiro do conteúdo celular; FDN = fibra em detergente neutro; $\mathrm{FDNi}=\mathrm{FDN}$ indigestível.
As determinações da matéria seca, matéria orgânica, proteína bruta, fibra em detergente neutro (FDN), fibra em detergente ácido (FDA), FDN corrigida para cinzas e proteína (FDNcp), extrato etéreo e matéria mineral dos ingredientes, dos suplementos, do pastejo simulado e das fezes foram realizadas de acordo com descrições de Silva \& Queiroz (2002). A determinação do nitrogênio insolúvel em detergente neutro (NIDN) e em detergnete ácido (NIDA) seguiram os métodos descritos por Van Soest et al. (1991).

A quantificação dos carboidratos não-fibrosos (CNF) dos suplementos foi realizada conforme adaptação de Hall (2000), em virtude da inclusão de ureia na composição dos suplementos, pela seguinte equação:

$\mathrm{CNF}=100-[(\% \mathrm{~PB}-\% \mathrm{~PB}$ da ureia $+\%$ ureia $)+\%$ FDNcp $+\% \mathrm{EE}+\%$ cinzas]

Os teores de carboidratos totais dos alimentos (CT) foram calculados segundo Sniffen et al. (1992):

$\mathrm{CT}=100-(\% \mathrm{~PB}+\% \mathrm{EE}+\%$ Cinzas $)$

Com base na composição químico-bromatológica dos alimentos, os teores de NDT foram estimados segundo o NRC (2001), pela equação:

$\mathrm{NDT}(\%)=(\mathrm{PBD}+\mathrm{CNFD}+\mathrm{FDNpD}+\mathrm{EED} \times 2,25)-7$, em que a constante 7 refere-se ao valor metabólico fecal.

Os teores de proteína degradável no rúmen (PDR) foram estimados de acordo com recomendações do NRC (2001): $\mathrm{PDR}=\mathrm{A}+\mathrm{B} *(\mathrm{Kd} / \mathrm{Kd}+\mathrm{Kp})$,

em que $\mathrm{A}$ = fração solúvel em água; $\mathrm{B}$ = fração insolúvel em água e potencialmente degradável; $\mathrm{Kd}$ = taxa de degradação da fração B; Kp = taxa de passagem da fração B da PB pelo rúmen. Os valores de A (\%), B (\%) e Kd (\%/hora) dos ingredientes utilizados foram obtidos de Valadares Filho et al. (2002) e o valor do Kp utilizado foi de $5 \%$ /hora.

A estimativa da excreção de MS fecal foi realizada considerando a razão entre a quantidade de indicador fornecido e sua concentração nas fezes:

Excreção fecal=[Quantidade fornecida do indicador (g)/concentração do indicador nas fezes] × 100

A concentração de FDNi foi determinada nas amostras de pastejo simulado, suplementos e fezes, por meio da digestibilidade in situ, obtida após incubação por 144 horas, segundo método descrito por Cochran et al. (1986). As estimativas do consumo voluntário foram obtidas empregando-se a equação: $\mathrm{CMS}=\{[(\mathrm{EF} \times \mathrm{CIF})-\mathrm{IS}] / \mathrm{CIFO}\}$ + CMSS em que, CMS (kg/dia) = consumo de matéria seca; $\mathrm{EF}=$ excreção fecal (kg/dia);

$\mathrm{CIF}=$ concentração do indicador nas fezes $(\mathrm{kg} / \mathrm{kg})$; IS = indicador presente no suplemento $(\mathrm{kg} / \mathrm{dia})$; CIFO = concentração do indicador na forragem $(\mathrm{kg} / \mathrm{kg})$ e CMSS = consumo de matéria seca de suplemento (kg/dia); 
A avaliação econômica do desempenho animal foi realizada observando a remuneração do capital investido, dividindo-se a margem de lucro pelas despesas envolvidas no processo de suplementação. A receita foi obtida pela multiplicação do ganho em equivalente carcaça (@) pelo valor da arroba na região $(\mathrm{R} \$ 58,00)$ e as despesas, pelo custo total com suplemento, considerando os valores de $\mathrm{R} \$ 0,49$ e $\mathrm{R} \$ 0,35 / \mathrm{kg}$ de suplemento, respectivamente, para os suplementos com farelo de soja e com farelo de algodão alta energia, e os custos de distribuição do suplemento. Nos custos de distribuição do suplemento, foi incluído o custo da hora mão-de-obra somado à hora-máquina observada na região $(\mathrm{R} \$ 25,00)$. Todas as cotações empregadas foram tomadas na região e no período em que foi conduzido o experimento. Considerou-se que foram necessários 25 minutos na distribuição do suplemento aos animais.

Ambos os experimentos foram estruturados e analisados em delineamento inteiramente casualizado em arranjo fatorial $2 \times 2$, com duas fontes de proteína (farelo de algodão de alta energia e farelo de soja) e duas frequências de fornecimento do suplemento (3 e 7 vezes por semana). Para avaliação do desempenho produtivo, empregou-se análise de covariância, segundo técnica descrita por Snedecor \& Cochran (1989), adotando-se como covariável o peso vivo inicial. Quando não foi observado efeito significativo para a covariável, o modelo foi reparametrizado, deslocando-se o grau de liberdade associado a essa fonte ao resíduo.

Quando necessário, os dados foram transformados para obedecer à normalidade dos resíduos e homogeneidade das variâncias. Os dados serão expressos na forma de médias e coeficiente de variação dos dados originais.

Os procedimentos estatísticos foram realizados pelo programa SAS (Statistical Analysis System), adotando
0,10 como nível crítico de probabilidade. Não houve interações fontes proteicas $\times$ frequência de suplementação para nenhuma das variáveis avaliadas, assim, os fatores (fonte proteica e frequência de suplementação) foram discutidos de forma isolada, exceto na avaliação econômica, na qual se entendeu como mais pertinente a apresentação e discussão dos resultados com base nas estratégias de suplementação pré-estabelecidas, por melhor representar os impactos das fontes proteicas aliadas às frequências de fornecimento do suplemento em um sistema de produção.

\section{Resultados e Discussão}

As disponibilidades médias de matéria seca total, matéria seca potencialmente digestível, matéria seca de folha verde, matéria seca de folha seca, matéria seca de colmo verde e matéria seca de colmo seco no pasto (Brachiaria brizantha, cv. Marandu) foram de 5.682, $3.817,576,1.684,2.078$ e $1.343 \mathrm{~kg}$ de MS/ha, respectivamente (Figura 1).

A disponibilidade da matéria seca total em todos os períodos experimentais permaneceu acima de $2.500 \mathrm{~kg}$ de MS/ha, valor mínimo necessário para não ocorrer limitação no consumo de MS pelos animais em pastagens de Brachiaria decumbens (Euclides et al., 1998). Todavia, Santos et al. (2004b) salientaram que a afirmação de que o aumento na disponibilidade de MS de forragem por meio da vedação aumenta a oportunidade de seleção de pasto nem sempre é verdadeira, uma vez que a vedação de gramíneas tropicais também pode conduzir a grande acúmulo de material senescente no relvado e esse material pode prejudicar o consumo de MS.

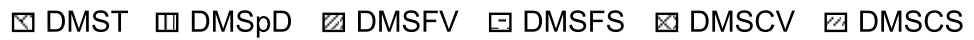

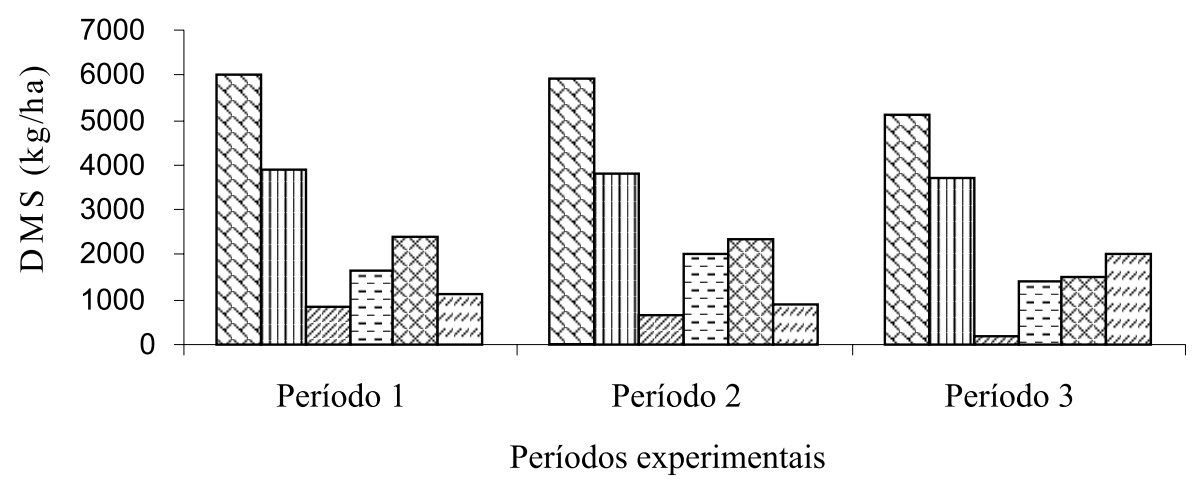

MST = matéria seca total; SpD = matéria seca potencialmente digestível; SFV = matéria seca de folha verde; SFS = matéria seca de folha seca; SCV = matéria seca de colmo verde; e SCS = matéria seca de colmo seco.

Figura 1 - Valores médios de disponibilidade de matéria seca nos períodos experimentais. 
Nos resultados das disponibilidades de MS dos componentes da forragem, a participação da folha verde na massa de forragem reduziu consideravelmente do início para o final do experimento (75,5\%), provavelmente como resultado do pastejo seletivo pelos animais, da redução na produção da forrageira e do aumento na taxa de senescência, correspondente a 842,67; 680,55; 206,85 kg de MSFV/ha, para os períodos 1,2 e 3 , respectivamente.

A disponibilidade de matéria seca de folha seca aumentou no segundo período e reduziu no terceiro, como resultado do início do período de transição seca-águas e da incorporação do material senescente ao perfil do solo.

Os valores de disponibilidade de colmo verde e colmo seco neste estudo foram bastante expressivos em todo o período experimental, perfazendo 36,5 e $23,6 \%$ da disponibilidade da MS total, respectivamente, provavelmente por tratar-se de um pasto de primeiro ano, com alto potencial de crescimento e longo período de diferimento.

De acordo com Paulino et al. (2006a), o aumento na utilização da forragem pode ser alcançado pela maior disponibilidade de MSpD aos animais e, concomitantemente, pela exploração dos aspectos positivos, ou redução dos aspectos negativos, da interação forragem $\times$ suplemento. Assim, o aumento na disponibilidade de MSpD possivelmente reduz as necessidades de inputs de recursos suplementares ao sistema. Neste estudo, a disponibilidade média de MSpD foi de aproximadamente $3.817 \mathrm{~kg}$ de MS/ha, que corresponde a $67,1 \%$ da disponibilidade da MS total.

O teor médio de $\mathrm{PB}$ da forragem amostrada via simulação do pastejo durante o período experimental foi de 4,01\% na MS (Tabela 2). De acordo com Van Soest (1994) e Lazzarini et al. (2009), as exigências de compostos nitrogenados dos microrganismos ruminais não são atendidas em níveis inferiores a 7\% de PB na dieta, o que poderia comprometer sobremaneira o crescimento dos microrganismos ruminais e a utilização da fração potencialmente degradável da fibra em detergente neutro.

Não houve influência $(\mathrm{P}>0,10)$ das fontes proteicas no ganho médio diário (Tabela 3). Embora a forragem seja a principal fonte energética para os bovinos em pastejo, durante o período seco do ano, partes dos nutrientes tornam-se indisponíveis, notadamente pelo efeito de proteção da lignina sobre os carboidratos fibrosos, o que incorre em elevada demanda por recursos suplementares

Tabela 2 - Composição nutricional da forragem e dos suplementos com farelo de soja e com farelo de algodão de alta energia (\%MS)

\begin{tabular}{|c|c|c|c|}
\hline \multirow[t]{2}{*}{ Item } & \multicolumn{2}{|c|}{ Fonte de proteína } & \multirow[t]{2}{*}{ Brachiaria $^{1}$} \\
\hline & Farelo de soja & $\begin{array}{l}\text { Farelo de algodão } \\
\text { alta energia }\end{array}$ & \\
\hline Matéria seca (\%) & 89,48 & 89,41 & 53,72 \\
\hline Matéria orgânica (\% da MS) & 91,60 & 91,36 & 90,07 \\
\hline Proteína bruta (\% da MS) & 35,23 & 35,15 & 4,01 \\
\hline Nitrogênio insolúvel em detergente neutro (\% do $\mathrm{N}$ total) & 2,22 & 6,09 & 39,26 \\
\hline Proteína degradável no rúmen $(\% \text { do } \mathrm{N} \text { total })^{2}$ & 74,61 & 77,96 & - \\
\hline Extrato etéreo (\% da MS) & 3,02 & 5,30 & 1,48 \\
\hline Matéria mineral (\% da MS) & 8,40 & 8,64 & 9,92 \\
\hline Fibra em detergente neutro (\% da MS) & 15,26 & 30,43 & 69,84 \\
\hline Fibra em detergente neutro corrigida para cinza e proteína (\% da MS) & 13,55 & 27,21 & 64,81 \\
\hline Fibra em detergente neutro insolúvel (\% da MS) & 2,88 & 12,48 & 23,44 \\
\hline Fibra em detergente ácido (\% da MS) & 8,65 & 22,23 & 39,83 \\
\hline Carboidratos não fibrosos (\% da MS) & 46,30 & 44,27 & 14,73 \\
\hline Lignina (\% da MS) & 3,00 & 4,68 & 6,49 \\
\hline Nutrientes digestíveis totais ${ }^{2}$ & 78,28 & 69,15 & - \\
\hline
\end{tabular}

${ }^{1}$ Simulação do pastejo; ${ }^{2}$ Estimado segundo o NRC (2001).

Tabela 3 - Ganho de peso de bovinos em pastejo recebendo suplementação proteica no período seco do ano

\begin{tabular}{|c|c|c|c|c|c|}
\hline \multirow[t]{2}{*}{ Variável } & \multicolumn{2}{|c|}{ Fonte de proteína } & \multicolumn{2}{|c|}{ Frequência } & \multirow[t]{2}{*}{ CV (\%) } \\
\hline & Farelo de soja & $\begin{array}{c}\text { Farelo de algodão } \\
\text { alta energia }\end{array}$ & 7 vezes/semana & 3 vezes/semana & \\
\hline Consumo de suplemento (g/dia) & 894,80 & 894,10 & 894,45 & 894,45 & - \\
\hline Peso vivo final (kg) & 261,00 & 254,18 & 255,62 & 259,71 & - \\
\hline Ganho médio diário (kg) & 0,630 & 0,540 & $0,500 \mathrm{~b}$ & $0,670 \mathrm{a}$ & 19,92 \\
\hline
\end{tabular}

${ }^{1}$ As comparações ocorreram dentro das fontes proteicas e depois dentro das frequências. 
(Van Soest, 1994; Paulino et al., 2006a). Logo, a suplementação proteica tem sido frequentemente utilizada, por seus benefícios sobre o ganho de peso dos animais, principalmente em condições de baixa qualidade da forragem, como neste estudo. Esse melhor desempenho decorrente do fornecimento de suplementos proteicos é resultado da correção de deficiências da proteína e/ou nitrogênio da dieta basal.

A ausência de diferenças entre as fontes proteicas utilizadas neste estudo deve-se ao fato de os suplementos utilizados serem isoproteicos. Além disso, as possíveis diferenças na degradabilidade da proteína dessas fontes, que poderiam promover desempenhos diferenciados, estão relacionadas à necessidade de diferentes participações de ureia na composição dos suplementos e/ou à capacidade de animais ruminantes em reciclar nitrogênio. Adicionalmente, de acordo com Van Soest (1994) a maior parte do nitrogênio utilizado pelos microrganismos ruminais que degradam a fibra encontra-se na forma de amônia e as bactérias são eficientes em assimilar amônia até satisfazer seus requerimentos. Desta forma, para melhoria do sistema pasto-suplemento em condições de baixa qualidade da forragem, como neste estudo, o farelo de algodão de alta energia pode ser utilizado como fonte de proteína verdadeira em suplementos múltiplos, pois proporciona desempenhos condizentes com aqueles preconizados para bovinocultura de ciclo curto em pastagem em condições de seca. Esse fato tem grande importância por ocasião da decisão de quais ingredientes serão utilizados na composição dos suplementos múltiplos.

Ambas as fontes proteicas possibilitaram ganhos superiores a $500 \mathrm{~g} /$ dia, o que tem grande importância quando se almeja a produção do novilho precoce a pasto para abate aos 24 meses de idade.

O ganho médio diário dos animais sob suplementação 3 vezes/semana foi superior ao obtido com suplementação diária, possivelmente em virtude da capacidade de animais ruminantes em reciclar nitrogênio e manter a digestão da fibra no rúmen entre os intervalos de suplementação de forma similar aos animais recebendo suplemento diariamente. Ambos os grupos consumiam semanalmente a mesma quantidade de suplemento, portanto, acredita-se que a ausência de interações entre fontes proteicas e frequência de suplementação também seja reflexo deste mecanismo de reciclagem endógena.

De acordo com Bohnert et al. (2002b) e Bohnert et al. (2002c), os ruminantes são hábeis em utilizar o nitrogênio suplementar e mantêm a eficiência microbiana e desempenho satisfatório mesmo quando a suplementação é realizada a intervalos maiores que um dia. Neste contexto, a manutenção de atenuado e prolongado pico de amônia ruminal nos intervalos de suplementação pode favorecer o processo digestivo e a conservação do nitrogênio.

Além disso, de acordo com Krehbiel et al. (1998) e Bohnert et al. (2002a), ruminantes consumindo forragem de baixa qualidade com suplementação em frequência irregular apresentam mudanças na permeabilidade do trato gastrointestinal e/ou mudanças na regulação renal da excreção de ureia, refletindo melhor utilização do nitrogênio nos intervalos de suplementação.

Embora não tenham sido realizadas avaliações do comportamento ingestivo dos animais em cada frequência de suplementação, os animais sob suplementação 3 vezes/ semana não consumiam o suplemento de uma só vez, principalmente aqueles recebendo farelo de algodão alta energia, cujo suplemento continha maior nível de ureia na sua composição. Esse fato contribuiu para a ausência de disputas e/ou dominância entre os animais no consumo do suplemento e para os benefícios nutricionais, como melhor sincronização amônia/energia, como relatado por Huston et al. (1999), que observaram menor variação no consumo em animais sob suplementação 3 vezes/semana (33\%) e 1 vez/semana (31\%) em comparação à suplementação diária.

Os resultados deste estudo contrariam informações de Garcia et al. (2005) de que a suplementação infrequente influencia negativamente o desempenho dos animais, uma vez que os ganhos foram de 234 e 124 g, respectivamente, para suplementação diária e 3 vezes/semana. Canesin et al. (2007) e Moraes et al. (2004), no entanto, avaliaram os efeitos do fornecimento infrequente de suplementos sobre o ganho de peso de bovinos em pastejo durante o período seco e não observaram diferenças entre as frequências de suplementação estudadas.

Neste estudo, a suplementação 3 vezes/semana parece ter resultado em ganho compensatório mais pronunciado que o obtido com a suplementação diária. Embora a quantidade semanal de suplemento fornecido para ambos os grupos (3 e 7 vezes/semana), esta variação esteve relacionada às maiores quantidades de suplemento oferecido aos grupos sob suplementação 3 vezes/semana.

Apesar da ausência de interação fonte proteica $\times$ frequência de fornecimento para o ganho de peso, os índices econômicos (Tabela 4) correspondem às estratégias pré-estabelecidas, por melhor representarem os impactos da combinação entre fonte proteica e frequência de fornecimento do suplemento.

O farelo de algodão, aliado à suplementação 3 vezes/ semana proporcionou os melhores resultados. As variações 
Tabela 4 - Ganho de peso total e remuneração do capital investido em cada frequência de suplementação

\begin{tabular}{|c|c|c|c|c|c|}
\hline \multirow[t]{2}{*}{ Item } & \multicolumn{4}{|c|}{ Estratégia de suplementação } & \multirow[t]{2}{*}{ CV (\%) } \\
\hline & $\begin{array}{c}\text { Farelo de soja } \\
7 \text { vezes/semana }\end{array}$ & $\begin{array}{c}\text { Farelo de soja } \\
3 \text { vezes/semana }\end{array}$ & $\begin{array}{c}\text { Farelo de algodão } \\
7 \text { vezes/semana }\end{array}$ & $\begin{array}{c}\text { Farelo de algodão } \\
3 \text { vezes/semana }\end{array}$ & \\
\hline Ganho de peso total (kg) & 46,28 & 59,60 & 37,76 & 53,00 & 22,37 \\
\hline Ganho médio diário (kg) & 0,55 & 0,71 & 0,45 & 0,63 & 19,01 \\
\hline Equivalente carcaça ${ }^{1}$ (@) & 1,60 & 2,06 & 1,31 & 1,83 & - \\
\hline Receita $^{2}(\mathrm{R} \$)$ & 93,05 & 119,84 & 75,98 & 106,57 & - \\
\hline Consumo de suplemento (kg) & 84,00 & 84,00 & 84,00 & 84,00 & - \\
\hline Custo do suplemento (R $\$ / \mathrm{kg})$ & 0,49 & 0,49 & 0,35 & 0,35 & - \\
\hline Custo de distribuição do suplemento ${ }^{3,4}$ ( $\mathrm{R} \$$ & 43,75 & 18,74 & 43,75 & 18,74 & - \\
\hline Despesa com suplemento ${ }^{5}(\mathrm{R} \$)$ & 41,16 & 41,16 & 29,40 & 29,40 & - \\
\hline Custo total $(\mathrm{R} \$)$ & 84,91 & 59,9 & 73,15 & 48,14 & \\
\hline Custo por arroba produzida (R\$) & 53,06 & 29,07 & 55,84 & 26,30 & - \\
\hline Margem bruta de lucro ${ }^{6}(\mathrm{R} \$)$ & 8,14 & 59,94 & 2,83 & 58,43 & - \\
\hline Remuneração capital investido (\%) & 10 & 100,06 & 3,80 & 121,37 & - \\
\hline
\end{tabular}

${ }^{1}$ Rendimento de carcaça - 52\%; ${ }^{2}$ Preço da arroba - R\$ 58,00; ${ }^{3}$ Hora homem+hora máquina - R\$ 25,00; ${ }^{4}$ Tempo necessário para distribuição suplemento - 0,4166 horas;

${ }^{5}$ Consumo médio do suplemento no período total multiplicado pelo seu custo $(\mathrm{R} \$ / \mathrm{kg}) ;{ }^{6}$ Lucro = receita - custo total; Valor do dólar no período - R\$ 1,89 .

no custo da suplementação atribuídas às fontes proteicas e à frequência de fornecimento constituíram-se o grande diferencial na remuneração do capital investido.

O custo do suplemento com farelo de algodão ( $\mathrm{R} \$ 0,35)$ foi inferior ao daquele com farelo de soja ( $\mathrm{R} \$ 0,49)$, o que permite inferir que o farelo de algodão de alta energia favorece a redução no custo do suplemento, constituindo-se numa fonte proteica alternativa na composição de suplementos múltiplos, pois possibilita ganhos próximos àqueles obtidos com farelo de soja. Além disso, os custos da suplementação diária foram maiores que os do fornecimento 3 vezes/semana, em razão do maior dispêndio com mão-de-obra e maquinário no processo de distribuição diária do suplemento.

Portanto, o fornecimento do suplemento em menor frequência (3 vezes/semana), além de constituir-se numa alternativa de manejo viável para otimização do desempenho animal, possibilita redução dos custos envolvidos no processo de suplementação e racionalização da mão-de-obra. Além disso, o farelo de algodão de alta energia e a frequência de fornecimento do suplemento (3 vezes/semana) representou o diferencial no custo da arroba produzida, na margem bruta de lucro e na remuneração do capital investido. De fato, segundo Paulino et al. (2006b), em uma bovinocultura de precisão desenvolvida em pastagem, são fundamentais tecnologias que envolvam a redução de custo do suplemento em si e sua distribuição nos pastos.

Assim como observado neste estudo, Gomes Jr. et al. (2002) avaliaram diferentes fontes proteicas e observaram que o suplemento à base de farelo de soja foi o de menor desempenho econômico, em virtude de seu custo relativamente elevado. Portanto, o retorno econômico depende das condições regionais e do período do ano em que os ingredientes são adquiridos.

A cada R \$ 1,00 investido, o retorno foi de $\mathrm{R} \$ 0,10$ e $\mathrm{R} \$ 1,00$ para o suplemento com farelo de soja fornecido 7 vezes/semana e 3 vezes/semana e R \$ 0,038 e R \$ 1,21 para o suplemento com farelo de algodão fornecido 7 vezes/ semana e 3 vezes/semana. Neste enfoque, a combinação farelo de algodão de alta energia e o fornecimento 3 vezes/ semana teve resultados econômicos mais favoráveis, devido aos menores custos do suplemento e de sua distribuição e ao maior ganho médio diário, o que resultou em menor custo por arroba produzida. Detmann et al. (2004) salientaram que a lucratividade do sistema não depende exclusivamente do desempenho animal, mas está altamente correlacionada às variações no mercado.

De acordo com Polizel Neto et al. (2006), maior escala de produção é fundamental para a viabilidade econômica de um sistema de produção pecuária, pois permite diluir significativamente os custos operacionais resultantes do tempo usado no transporte do suplemento em relação ao número de animais beneficiados. Logo, a suplementação em baixa frequência, aliada a maior escala de produção, pode proporcionar índices econômicos satisfatórios, tendo em vista a expressiva redução nos custos operacionais.

Neste contexto, além dos benefícios econômicos da suplementação, deve-se atentar aos benefícios indiretos desta técnica, principalmente quanto à desocupação das pastagens para outras categorias e maior giro de capital. Do ponto de vista estratégico, o ambiente de comercialização da arroba produzida e o custo dos ingredientes utilizados na formulação dos suplementos são de grande importância nas análises econômicas e devem ser considerados nas 
decisões, uma vez que qualquer alteração de mercado favorável pode aumentar os índices econômicos.

No experimento 2, a disponibilidade de matéria seca total foi de $4.778 \mathrm{~kg} / \mathrm{ha}$; a de matéria seca potencialmente digestível, de $4.204 \mathrm{~kg} / \mathrm{ha}$; a de matéria seca de folha verde, de $274 \mathrm{~kg} / \mathrm{ha}$; a de matéria seca de folha seca, de $1.264 \mathrm{~kg} / \mathrm{ha}$; a de matéria seca de colmo seco, de $950 \mathrm{~kg} / \mathrm{ha}$; e a de matéria seca de colmo seco, de $2.288 \mathrm{~kg} / \mathrm{ha}$. É importante ressaltar o início do período de transição secaáguas, caracterizado pelo aparecimento de brotos novos e tenros na forragem. Logo, a disponibilidade de MS de folha verde, e consequentemente a de MS potencialmente digestível, no experimento 2 foi maior que no experimento 1 .

Como resultado das novas brotações, o teor de FDN no experimento 2 foi menor que no experimento 1 , enquanto o de proteína bruta da forragem foi elevado (Tabela 5), com valor bem superior $(11,31 \%)$ ao limite mínimo necessário, de 7\%, relatado por Minson (1990) e Van Soest (1994) para o não-comprometimento da atividade da microbiota ruminal.

Não houve efeito da frequência de suplementação $(\mathrm{P}>0,10)$ sobre os consumos de MS total e MS de pasto nem sobre os consumos de nutrientes da dieta (Tabela 6). Esses resultados são semelhantes aos encontrados por Krehbiel et al. (1998), Farmer et al. (2004b) e Moraes et al. (2010), o que está relacionado às não-diferenças no tempo despendido com atividade de pastejo entre animais sob suplementação diária ou três vezes por semana (Beaty et al., 1994).

Em contraste, Beaty et al. (1994) e Huston et al. (1999) observaram maior consumo de MS de forragem com suplementação diária em comparação à suplementação
Tabela 5 - Composição nutricional da Brachiaria brizantha cv. Marandu (\% MS)

\begin{tabular}{lc}
\hline Item & Brachiaria $_{\text {brizantha }}$ \\
\hline Matéria seca (\%) & 24,64 \\
Matéria orgânica $^{2}$ & 90,04 \\
Proteína bruta $^{2}$ & 11,31 \\
Nitrogênio insolúvel em detergente neutro $^{3}$ & 32,25 \\
Nitrogênio insolúvel em detergente ácido & 9,01 \\
Extrato etéreo $^{2}$ & 0,96 \\
Matéria mineral $^{2}$ & 9,95 \\
Fibra em detergente neutro $^{2}$ & 58,21 \\
Fibra em detergente neutro insolúvel $^{2}$ & 13,74 \\
Fibra em detergente ácido $^{2}$ & 32,96 \\
Carboidratos totais $^{2}$ & 77,76 \\
Carboidratos não-fibosos $^{2}$ & 19,55 \\
Lignina $^{2}$ & 4,49 \\
\hline
\end{tabular}

${ }^{1}$ Simulação do pastejo; ${ }^{2} \%$ da MS; ${ }^{3} \%$ do $\mathrm{N}$ total.

3 vezes/semana. Segundo esses autores, esse decréscimo no consumo associado à suplementação 3 vezes/semana pode estar relacionado à maior quantidade de suplemento fornecido aos animais desse grupo nos dias de suplementação. Neste estudo, possivelmente isso não ocorreu, em virtude do baixo nível de suplementação, que evita o efeito substitutivo, ou seja, redução no consumo de forragem em decorrência do consumo de suplemento.

O consumo de MS total neste estudo foi inferior ao observado por Moraes et al. (2010), de aproximadamente 2,2\% do PV. Várias podem ser as causas deste menor consumo, mas boa parte está relacionada às alterações na estrutura do relvado no início do período de transição secaáguas, uma vez que, segundo Paulino et al. (2002), os animais rejeitam a forragem seca e preferem as brotações novas, ainda escassas e insuficientes para atender o consumo.

Tabela 6 - Consumos de matéria seca total, matéria seca e matéria orgânica do pasto e dos nutrientes da dieta

\begin{tabular}{|c|c|c|c|c|c|c|}
\hline \multirow[t]{2}{*}{ Item } & \multicolumn{2}{|c|}{ Fonte de proteína } & \multicolumn{3}{|c|}{ Frequência de fornecimento } & \multirow[t]{2}{*}{ CV (\%) } \\
\hline & Farelo de soja & Farelo de algodão & 7 & vezes/semana & 3 vezes/semana & \\
\hline \multicolumn{7}{|c|}{$\mathrm{kg} / \mathrm{dia}$} \\
\hline Matéria seca total & 3,19 & 3,51 & & 3,42 & 3,27 & 25,81 \\
\hline Matéria seca de pasto & 2,30 & 2,62 & & 2,52 & 2,37 & 35,16 \\
\hline Matéria orgânica & 2,89 & 3,17 & & 3,09 & 2,96 & 25,70 \\
\hline Matéria orgânica de pasto & 2,07 & 2,35 & & 2,27 & 2,14 & 35,16 \\
\hline Proteína bruta & 0,57 & 0,61 & & 0,60 & 0,58 & 16,53 \\
\hline Extrato etéreo ${ }^{1}$ & $0,05 b$ & $0,07 \mathrm{a}$ & & 0,06 & 0,06 & 23,70 \\
\hline Carboidratos totais & 2,27 & 2,49 & & 2,43 & 2,31 & 28,22 \\
\hline Fibra em detergente neutro & 1,47 & 1,79 & & 1,67 & 1,58 & 31,79 \\
\hline Carboidratos não-fibrosos & 0,86 & 0,90 & & 0,89 & 0,87 & 18,97 \\
\hline \multicolumn{7}{|c|}{$\% \mathrm{PV}$} \\
\hline Matéria seca total & 1,26 & 1,41 & & 1,39 & 1,27 & 28,94 \\
\hline Matéria seca de pasto & 0,91 & 1,05 & & 1,02 & 1,04 & 37,57 \\
\hline Matéria orgânica & 1,14 & 1,27 & & 1,26 & 1,15 & 28,84 \\
\hline Matéria orgânica de pasto & 0,82 & 0,94 & & 0,92 & 0,84 & 37,57 \\
\hline Fibra em detergente neutro & 0,58 & 0,72 & & 0,68 & 0,61 & 34,68 \\
\hline
\end{tabular}

\footnotetext{
${ }^{1}$ As comparações foram feitas dentro das fontes proteicas e depois dentro das frequências.
} 
A fonte proteica teve efeito $(\mathrm{P}<0,10)$ apenas sobre $\mathrm{o}$ consumo de extrato etéreo e esse efeito foi maior nos animais sob suplementação com farelo de algodão, em decorrência da maior concentração desse nutriente nesse alimento (Tabela 2).

$\mathrm{Na}$ análise da digestibilidade, as fontes proteicas influenciaram $(\mathrm{P}<0,10)$ apenas a digestibilidade da $\mathrm{PB}$, que foi maior nos animais sob suplementação com farelo de algodão, provavelmente em razão da maior participação de ureia na composição desse suplemento, que é rapidamente hidrolisada à amônia no ambiente ruminal.

Não houve efeito $(P>0,10)$ das frequências de suplementação sobre a digestibilidade dos nutrientes da dieta (Tabela 7), possivelmente em virtude da capacidade dos animais ruminantes em amenizar os efeitos do baixo suprimento de nutrientes e manter sua digestibilidade, mesmo nos dias sem suplementação.

Esses resultados são semelhantes aos encontrados por Moraes (2006), que avaliou várias frequências de suplementação e não observou efeito na digestibilidade aparente dos nutrientes da dieta. Beaty et al. (1994), no entanto, notaram que a suplementação 3 vezes/semana aumentou a digestibilidade da MS e da FDN da dieta em comparação à suplementação diária e atribuiu esse resultado ao menor consumo de forragem e à taxa de passagem mais lenta da digesta nos animais sob suplementação 3 vezes/semana.

Farmer et al. (2004b) também salientaram a habilidade de ruminantes em manter a digestão da fibra mesmo em situações de suplementação irregular e reforçaram o fato de ruminantes possuírem mecanismos capazes de inibir os efeitos do fornecimento infrequente de nutrientes. Por outro lado, Farmer et al. (2001) e Farmer et al. (2004a) verificaram redução nas digestibilidades da MO e da FDN da dieta quando bovinos receberam suplementação em dias alternados.

De modo geral, a ausência de efeitos negativos das fontes protéicas e da frequência de suplementação sobre o consumo e a digestibilidade dos nutrientes reflete a possibilidade de adequação dos parâmetros nutricionais dos animais por meio da utilização do farelo de algodão de alta energia e do fornecimento de suplemento 3 vezes/semana.

Tabela 7 - Digestibilidade dos nutrientes das dietas

\begin{tabular}{|c|c|c|c|c|c|}
\hline \multirow[t]{2}{*}{ Item } & \multicolumn{2}{|c|}{ Fonte de proteína } & \multicolumn{2}{|c|}{ Frequência de fornecimento } & \multirow[t]{2}{*}{ CV (\%) } \\
\hline & Farelo de soja & Farelo de algodão & 7 vezes/semana & 3 vezes/semana & \\
\hline & \multicolumn{4}{|c|}{ Digestibilidade } & \\
\hline Matéria seca & 51,82 & 44,36 & 45,57 & 51,21 & 25,48 \\
\hline Matéria orgânica & 55,02 & 50,35 & 50,31 & 55,62 & 21,16 \\
\hline Proteína bruta & $54,92 b$ & $64,76 a$ & 59,55 & 60,56 & 18,22 \\
\hline Carboidratos totais & 58,52 & 50,35 & 51,83 & 57,57 & 21,44 \\
\hline Fibra em detergente neutro & 39,47 & 36,96 & 36,54 & 40,00 & 23,46 \\
\hline Carboidratos não-fibrosos & 87,13 & 88,81 & 87,21 & 89,12 & 9,00 \\
\hline
\end{tabular}

${ }^{1}$ As comparações ocorreram dentro das fontes proteicas e depois dentro das frequências.

\section{Conclusões}

O fornecimento de suplemento três vezes por semana para bovinos de corte em recria no período seco é viável, pois, além de reduzir os custos da suplementação, possibilita desempenho superior ao obtido com a suplementação diária. A utilização do farelo de algodão de alta energia em suplementos múltiplos em substituição ao farelo de soja é satisfatória, principalmente do ponto de vista econômico. Logo, a combinação farelo de algodão de alta energia e a suplementação 3 vezes/semana permite reduzir os custos de produção e aumentar a rentabilidade ao sistema.

\section{Referências}

BEATY, J.L.; COCHRAN, R.C.; LINTZENICH, B.A. et al. Effect of frequency of supplementation and protein concentration in supplements on performance and digestion characteristics of beef cattle consuming low-quality forages. Journal of Animal Science, v.72, p.2475-2486, 1994.

BOHNERT, D.W.; SCHAUER, C.S.; BAUER, M.L. et al. Influence of rumen protein degradability and supplementation frequency on steers consuming low-quality low-quality forage: I-Site of digestion and microbial efficiency. Journal of Animal Science, v.80, p.2967-2967, 2002b.

BOHNERT, D.W.; SCHAUER, C.S.; DELCURTO, T. Influence of rumen protein degradability and supplementation frequency on performance and nitrogen use in ruminants consuming low-quality forage: Cow performance and efficiency of nitrogen use in wethers. Journal of Animal Science, v.80, p.1629-1637, 2002a. 
BOHNERT, D.W.; SCHAUER, C.S.; FALCK, S.J. et al. Influence of rumen protein degradability and supplementation frequency on steers consuming low-quality low-quality forage: II - Ruminal fermentation characteristics. Journal of Animal Science, v.80, p.2978-2988, 2002c.

CANESIN, R.C.; BERCHIELLI, T.T.; ANDRADE, P. et al. Desempenho de bovinos de corte mantidos em pastagem de capim marandu submetidos a diferentes estratégias de suplementação no período das águas e da seca. Revista Brasileira de Zootecnia, v.36, n.2, p.411-420, 2007.

COCHRAN, R.C.; ADAMS, D.C.; WALLACE, J.D. et al. Predicting digestibility of different diets with internal markers: evaluation of four potential markers. Journal of Animal Science, v.63, n.5, p.1476-1483, 1986.

DETMANN, E.; PAULINO, M.F.; ZERVOUDAKIS, J.T. et al. Níveis de proteína bruta em suplementos múltiplos para terminação de novilhos mestiços em pastejo durante a época seca: desempenho produtivo e características de carcaça. Revista Brasileira de Zootecnia, v.33, n.1, p.169-180, 2004.

FARMER, C.G.; COCHRAN, R.C.; NAGARAJA, T.G. et al. Ruminal and host adaptaptations to change in frequency of protein supplementation Journal of Animal Science, v.82, p.895-903, 2004b

FARMER, C.G.; COCHRAN, R.C.; SIMMS, D.D. et al. The effects of several supplementation frequencies on forage use and the performance of beef cattle consuming dormant tallgrass prairie forage. Journal of Animal Science, v.79, p.2276-2285, 2001.

FARMER, C.G.; WOODS, B.C.; COCHRAN, R.C. et al. Effect of supplementation frequency and supplemental urea level on dormant tallgrass-prairie hay intake and digestion by beef steers and prepartum performance of beef cows grazing dormant tallgrass-prairie. Journal of Animal Science, v.82, 884-894, 2004a.

GARCIA, L.F.; FERNANDES, L.B.; FRANCO, A.V. et al. Desempenho de bovinos em pastejo contínuo submetidos a dois intervalos de suplementação no período da seca. In: REUNIÃO ANUAL DA SOCIEDADE BRASILEIRA DE ZOOTECNIA, 42. 2005, Goiânia. Anais... Goiânia: Sociedade Brasileira de Zootecnia, 2005. (CD-ROM).

GOMES JÚNIOR, P.; PAULINO, M.F.; DETMANN, E. et al. Desempenho de novilhos mestiços na fase de crescimento suplementados durante a época seca. Revista Brasileira de Zootecnia, v.31, n.1, p.139-147, 2002.

HALL, M.B. Calculation of non-structural carbohydrate content of feeds that contain non protein nitrogen. University of Florida, 2000. p.A-25 (Bulletin 339).

HUSTON, J.E.; LIPPKE, H.; FORBES, T.D. et al. xEffects of supplemental feeding interval on adult cows in western Texas. Journal of Animal Science, v.77, p.3057-3067, 1999.

KREHBIEL, C.R.; FERRELL, C.L.; FREETLY, H.C. Effects of frequency of supplementation on Dry matter intake and net portal and hepatic flux of nutrients in mature ewes that consume low-quality forage. Journal of Animal Science, v.76, p.24642473, 1998.

LAZZARINI, I.; DETMANN, E.; SAMPAIO, C.B. et al. Intake and digestibility in cattle fed low-quality tropical forage and supplemented with nitrogenous compounds. Revista Brasileira de Zootecnia, v.38, n.10, p.2021-2030, 2009.
MINSON, D.J. Forage in ruminant nutrition. New York: Academic Press, 1990. 483p.

MORAES, E.H.B.K.; PAULINO, M.F.; ZERVOUDAKIS, J.T. et al. Associação de diferentes fontes energéticas e protéicas em suplementos múltiplos na recria de novilhos mestiços sob pastejo no período da seca. Revista Brasileira de Zootecnia, v.35, n.3, p.914-920, 2006

MORAES, E.H.B.K.; PAULINO, M.F.; VALADARES FILHO, S.C. et al. Avaliação nutricional de estratégias de suplementação para bovinos decorte durante a estação da seca. Revista Brasileira de Zootecnia, v.39, n.3, p.608-616, 2010.

NATIONAL RESEARCH COUNCIL - NRC. Nutrients requirements of dairy cattle. 7.ed. Washington, D.C.: National Academy Press, 2001. 381p.

POLIZEL NETO, A.P.; ZERVOUDAKIS, J.T.; CABRAL, L.S. et al. Frequência de suplementação de bovinos nelore durante o período das águas: análise econômica. In: REUNIÃO ANUAL DA SOCIEDADE BRASILEIRA DE ZOOTECNIA, 43., 2006, João Pessoa. Anais... João Pessoa: Sociedade Brasileira de Zootecnia, 2006 (CD-ROM).

PAULINO, M.F.; DETMANN, E.; VALADARES FILHO, S.C. Suplementação animal em pasto: energética ou protéica? In: SIMPÓSIO SOBRE MANEJO ESTRATÉGICO DA PASTAGEM, 3., 2006, Viçosa, MG. Anais... Viçosa, MG, 2006a. p.359-392.

PAULINO, M.F.; ZAMPERLINI, B.; FIGUEIREDO, D.M. et al. Bovinocultura de precisão em pastagens. In: SIMPÓSIO DE PRODUÇÃO DE GADO DE CORTE, 5., SIMPÓSIO INTERNACIONAL DE PRODUÇÃO DE GADO DE CORTE, 1., 2006, Viçosa, MG. Anais... Viçosa, MG: SIMCORTE, 2006b. p.361-411.

PAULINO, M.F.; ZERVOUDAKIS, J.T.; MORAES, E.H.B.K. et al. Bovinocultura de ciclo curto em pastagens. In: SIMPÓSIO DE PRODUÇÃO DE GADO DE CORTE, 3., 2002, Viçosa, MG. Anais... Viçosa, MG: SIMCORTE, 2002. p.153-196.

SANTOS, D.T.; ROCHA, M.G.; GENRO, T.C.M. et al. Suplementos energéticos para recria de novilhas de corte em pastagens anuais. análise econômica. Revista Brasileira de Zootecnia, v.33, n.6, p.2359-2368, 2004a (supl. 3).

SANTOS, E.D.G.; PAULINO, M.F.; QUEIROZ, D.S. et al. Avaliação de pastagem diferida de Brachiaria decumbens stapf. 2. Disponibilidade de forragem e desempenho animal durante a seca. Revista Brasileira de Zootecnia, v.33, n.1, p.214-224, 2004b.

SILVA, D.J.; QUEIROZ, A.C. Análise de alimentos: métodos químicos e biológicos. 3.ed. Viçosa, MG: Universidade Federal de Viçosa, 2002. 235p.

SNEDECOR, G.W.; COCHRAN, W.G. Statistical methods. 8.ed. Iowa: Iowa University Press, 1989. 503p.

SNIFFEN, C.J.; O’CONNOR, J.D.; VAN SOEST, P.J. et al. A net carbohydrate and protein system for evaluating cattle diets; II. Carbohydrate and protein availability. Journal of Animal Science, v.70, n.11, p.3562-3577, 1992.

VALADARES FILHO, S.C.; ROCHA JR., V.R.; CAPELLE, E.R. Tabelas brasileiras de composição de alimentos para bovinos. Viçosa, MG: DZO, DPI, UFV, 2002. 297p.

VAN SOEST, P.J. Nutritional ecology of the ruminant. 2.ed. Ithaca: Cornell University, 1994. 476p.

VAN SOEST, P.J.; ROBERTSON, J.B.; LEWIS, B.A.; Methods for dietary fiber, Neutral detergent fiber, and nonstarch polysaccharides in relation to animal nutrition. Journal of Dairy Science, v.74, n.10, p.3583-3597, 1991. 